\title{
Building Information Modelling: a study into the suitability of BIM within projects with construction values of less than $\mathfrak{£ 5 M}$
}

\author{
R. Watt \\ Brunel University, UK
}

\begin{abstract}
Building Information Modelling (BIM) is gaining momentum to soon become the construction industry's chosen methodology for delivering projects. However, studies have shown that the implementation rate of BIM in smaller consultancies is notably lower when compared to larger ones. One of the main reasons for resisting implementation is the perceived notion that lower value projects are not suitable for the use of BIM. With this in mind, this study aims to determine if projects with a lower construction value are suitable for the BIM methodology.

A data set has been generated that included individuals who have and have not implemented BIM within their workflow, the results of which have been collated from questionnaires and interviews. From the data set, conclusions were derived, which make up the findings of this report.

The study found that there is a clear relationship between the individual's experience of BIM and their perceived impression of BIM's suitability within smaller valued projects. Individuals and companies who have fully implemented BIM within their workflow highlighted significant advantages and frustrations, that are valid, both on smaller and larger valued projects. Within the experienced community of BIM users, it is evident that BIM has been and can successfully be used on projects of any value, providing that the methodology is managed correctly.
\end{abstract}

Keywords: Building Information Modelling (BIM), low value projects, implementation, client demand, capital cost. 


\section{Introduction}

The use and awareness of Building Information Modelling (BIM) has been growing throughout the construction industry over the years [1]. The methodology of BIM is set to replace the paradigm of information transmittals of twodimensional Computer-Aided Design (CAD) drawings and specifications [2]. The methodology of BIM will provide a system whereby all of the information to design, construct, use and maintain a building is contained within a singular information model, rather than information contained in many mediums [3].

BIM has been hailed as providing many advantages, with the top two being better collaboration and cost savings, as outlined within the Government's Industrial Strategy report on BIM [4]. The Government has set the target that all government-funded projects shall be fully collaborative with 3D BIM by 2016, which equates to a BIM Level 2 [5].

This study set out to determine if BIM Level 2 is suitable for smaller valued projects and to find evidence regarding when and where BIM is not suitable in relation to project value.

\subsection{What is BIM?}

The Government explains BIM as being "a collaborative way of working, underpinned by the digital technologies which unlock more efficient methods of designing, creating and maintaining our assets" [4]. BIM is a methodology, generally only becoming possible due to the advancements with computers and software, even though the basics of BIM were outlined in the late 1970s [6].

BIM is a methodology of transferring information through the use of a collaborative model referred to as a virtual prototype [6]. The model itself is rich in data and carries all the information for the project from conception through to demolishment of the building [6].

This is a significant change from the previous methodology of transferring information through the use of two-dimensional drawings and hard-copy specifications. BIM allows for this information to be replicated using a single model to generate 3D drawings, sections and schedules. By editing one of the items within the model, all other information will be changed simultaneously [6].

The methodology of BIM outlines four levels, starting at level zero and ending at three. The levels are as follows:

- Level Zero: Unmanaged CAD in 2D.

- Level One: Managed CAD in 2D or 3D to an agreed structure.

- Level Two: Managed 3D with data attached to the model following an agreed standardised structure. Models are separate from each discipline.

- Level Three: Fully integrated model with all the disciplines [5].

\subsection{Background to the project}

There are a number of publications that highlight the advantages of BIM and claim significant savings by the use and implementation of BIM throughout the workflow. 
The examples given in the literature are often referencing large developments such as hospitals, airports and large office blocks. There are a limited number of publications that directly reference the use of BIM within small projects. With this in mind, this study was set up to provide a better understanding of BIM's suitability in relation to smaller projects.

\subsection{Scope of the study}

The study set out to investigate if or when BIM becomes unsuitable on smaller valued projects by focusing on the following points:

- What impression do people have of the BIM methodology in relation to lower value projects?

- What are the key advantages and disadvantages of BIM and are they experienced on lower value projects?

- What are the key areas of resistance and motivation towards the implementation of BIM?

- Is there a point where the BIM methodology becomes unsuitable to use on a project?

Based on the above, the project title of 'a study into the suitability of BIM within projects with construction values of less than $£ 5 \mathrm{~m}$ ’ was chosen.

\subsection{Clarifications}

\subsubsection{Reference to BIM}

For clarification, when the report refers to BIM integration, it is with reference to 'Level 2', unless otherwise stated.

\subsubsection{Lower value projects}

The study has outlined a project value range of up to $£ 5 \mathrm{M}$ but this should be used as a guide only. The main purpose of the selected range is to exclude large developments such as hospitals, stadiums or airports, where many examples of BIM's use have been provided in other studies and publications. Therefore, when this study references a 'lower value project', it is effectively comparing that project with the high value projects stated above.

\subsubsection{Suitability}

For the purpose of this report, if the BIM methodology can be adapted to suit the project and to achieve a net positive impact, then BIM can be deemed suitable for the project.

\section{Literature review}

The purpose of this literature review is to provide background information relevant to the study's title. Based on the study's scope, two main topic areas have been outlined and they are as follows:

- Current perception of BIM on lower value projects; and

- Scalability. 
Following the literature review, this review will summarise its findings and outline questions that this study should aim to address.

\subsection{Perception of BIM on lower value projects}

The NBS report outlined that, within their sample, only $35 \%$ of small practices with six or fewer personnel are using BIM, whereas in larger practices $61 \%$ are using BIM [1]. However, one of the contributors to the report outlines that, in practice, BIM should be easier to implement within a smaller company due to their relative agility [1]. This means that, if in theory, it is easier to implement BIM into a smaller practice then there are likely to be other factors contributing to the low perception of BIM, rather than just the relative implementation cost.

The perception that BIM may not be suitable for lower value projects is outlined in the author's foreword of the publication 'BIM in Small Practices: Illustrated Case Studies' by Klaschka [7], by stating, "Myth 1 - BIM is for large projects. No! Examples in this book include residential conversions, extensions and a self-build house." The author indicates that the general perception of BIM in the wider community is that it is not suitable for smaller, lower value projects. He is keen to point out that this impression is unjustified.

Based on the literature, it is understood that the overall impression with regards to lower value projects could be deemed to be relatively low, when compared to the impression of its suitability on larger valued projects.

\subsection{Scalability}

\subsubsection{Areas of support}

An article by Dawes [8] indicated that companies were able to scale down their role within the design team to suit smaller projects, without losing the merit of using BIM. Dawes' article is concentrated around a £1-2 million residential development, with varying sized buildings within the development. She noted that they had to make extensive changes to their standard BIM documentation over the course of the project. However, she highlighted that the majority of the amended information could be reused within further projects. Thus, meaning that they are now able to achieve greater efficiencies on their future projects.

Further support for BIM within smaller projects can be found in an article titled 'BIM Application for Integrated Design and Engineering in Small-Scale Housing Development: A Pilot Project in the Netherlands' [9]. The document concluded that Small and Medium Enterprises (SME) had a much greater integrated design process and were able to carry out 'clash detection' throughout the design process.

David Miller of David Miller Architects has been an advocate in the use of BIM and Revit for many years [10]. Within an article for NBS, titled 'BIM From The Point Of View Of A Small Practice' [10], he outlines how his practice has rolled out the use of BIM. In general, his practice budgets $£ 10,000$ per workstation; he notes however, that the added advantages of increased efficiency and added value quickly outweighs the increased capital expenditure. From the text, it is not clear what sized projects he believes that these advantages occur within, but the comments are reflective of an architecture firm of 14 employees. Based on the 
practice size it can be assumed that he has found the use of BIM to be a positive experience on various size projects.

In an article published within the 'International Journal of Project Management', the authors indicated that, within their investigation of 35 case studies, ranging from project values of 12 million to 1,715 million Euros, "no strong pattern emerges in respect of the type or size of building, which BIM is more or less beneficial" [11]. This further supports the notion that BIM can be suitable on all projects and is not limited to large developments.

\subsubsection{Areas of resistances}

As highlighted within the 'Perception of BIM on Lower Value Projects' section of this study, a text outlined the following "Myth $1-$ BIM is for large projects. No! Examples in this book include residential conversions, extensions and a selfbuild house" [7]. It is clear that the author is stating two key points: the first point is that there is an impression that BIM is only suitable on larger projects, and the second point is that this impression is unjustified. In the same manner, the Architectural Evangelist reiterates: "Often misquoted, BIM is only for large projects with complex geometries" [12].

\subsubsection{Summary}

We can conclude from the study's literature review, that there is evidence that BIM has been scaled down to be suitable on smaller value projects. Contrary to this, we have seen that there is evidence to suggest that the overall confidence of BIM within smaller projects is low. However, there was insufficient evidence to indicate where and when BIM becomes unsuitable in relation to a project's value.

\subsection{Literature review summary}

The literature review has highlighted that the current perception of BIM is generally positive, but there is still a lot of uncertainty about its use. There are traces of evidence to suggest that if you are not a BIM expert, then your perception of BIM suitability reduces significantly when faced with lower value projects.

BIM will require a large change in a building's workflow, a large change in the way that buildings are designed and a change in how they are built. It will require all teams to work more efficiently to ensure that BIM implementation is achieved. This has the potential for information to be shared more easily, at a quicker rate and at a magnitude that has never been seen before. This can lead to further opportunities to add other areas of value that have not been available before the implementation of BIM.

Throughout the literature review there was insufficient evidence to demonstrate that BIM is unsuitable on lower valued projects; however, there also appears to be a strong uncertainty for its application on such projects.

\subsection{Questions raised from the literature review}

The review outlined that there appears to be a disparity between the overall construction industry's impression of BIM within smaller projects and published 
findings. The first question raised is: "Is there a clear relationship between the perceived suitability of BIM on lower value projects and an individual's experience of BIM?"

There appears to be a lot of material that promotes the use of BIM, however there is not much evidence on why companies have not implemented BIM. Thus, the second question raised is: "What are the main reasons why companies/individuals are not currently using BIM on lower value projects, and what evidence is available to support the resistances?"

The review outlined that there are case studies that show benefits for the use of BIM, but the case studies did not highlight the negatives. This leads to the third question: "What have been the main advantages and disadvantages for implementing BIM on lower value projects, and overall would companies or individuals recommend BIM on lower value projects?"

The following study will aim to answer the above questions, together with the overall question: When does BIM become unsuitable for use based on project value?

\section{Data acquisition}

To provide a better understanding on the suitability of BIM within lower value projects, a data set has been generated with both primary and secondary data. The following section will outline the sources of the said data.

\subsection{Primary data}

Primary data was generated by the following:

- Individual Surveys: Forty-one of the estimated one hundred participants returned a compliant individual survey. The respondents came predominantly from architects and building services engineers from various size consultancies with a broad range of experience in using BIM. They ranged from individuals who have not yet used BIM to ones who have fully integrated it within their workflow.

- Project Surveys: The respondents from the individual survey were asked to respond to a project specific survey. Four compliant responses were returned. It is noted that this data set is not sufficient to draw specific conclusions, however the comments made and examples given were highly useful when supporting theories and conclusions.

- Interviews: Four individuals who are either BIM managers within their company or hold a senior position. Each interview was carried out over the telephone, with set questions to allow for comparisons between respondents.

\subsection{Secondary data}

NBS National BIM Report 2014 [1]: The secondary data set was introduced into the study to allow comparisons between the primary and secondary data. The purpose of this is to identify if this study's findings run in parallel to a wider survey 
that did not concentrate on lower value projects but rather the whole construction industry.

\section{Data analysis}

\subsection{Introduction}

The following section will analyse the data that was obtained and aims to provide a better insight into the literature review questions as well as the overall study's title.

The sections have been split into the following headings: Data Validation and Quality, Literature Review Questions and Discussion of Results.

\subsection{Data validation and quality}

The data obtained was processed under the following processes: data validation, data segregation and data error checks, prior to its inclusion within the study.

The quantitative data obtained within the individual surveys was segregated between individuals who have implemented BIM (73\% of 41) and those who have not $(27 \%$ of 41$)$. The qualitative data was analysed using the methodology of Grounded Theory [13] from which theories were drawn.

Data from within the study predominantly came from independent primary sources. The respondents had no direct initial gain in relation to the results of this study. The data was obtained in a scientific nature with careful consideration of limiting data error. The data set and sectors were of a suitable size and nature to provide a good, unbiased, diverse response.

\subsection{Literature review questions}

Following a literature review, three main questions were derived (refer to section 2.4). This subsection will address the questions.

\subsubsection{Question 1}

"Is there a clear relationship between the perceived suitability of BIM on lower valued projects and an individual's experience of BIM?"

Throughout the data set there was a constant trend that a person's impression of BIM was lower on many factors, such as: perceived capital cost, client demand and project productivity. The latter provided a key metric since it indicated their clear swing of opinion. The individuals who have not used BIM believed that BIM was unsuitable on lower value projects, whereas individuals who have implemented BIM thought the opposite. This strengthens the trend that the more BIM experience a respondent had, the higher their impression of BIM would be, in relation to its suitability in smaller value projects.

Based on the study's findings, the following statement can be derived: "The perceived suitability of BIM within lower value projects is proportional to an individual's experience". 


\subsubsection{Question 2}

"What are the main reasons why companies/individuals are not currently using BIM on lower value projects, and what evidence is available to support the resistances?"

The questionnaires highlighted that the main reason for the nonimplementation of BIM to date is that there is a perceived low client and design team demand. This is coupled with a significant learning curve and high perceived capital cost. BIM implementation has therefore not been their priority. Underlying this, is their perceived impression that BIM is unsuitable for smaller valued projects (discussed above). Throughout the study however, no evidence was given to indicate that individuals have validated their impressions by testing the BIM methodology within their workflow.

Based on the study's findings, the following statement can be derived: "The main reasons why individuals and companies have not implemented BIM within their workflow is due to the perceived large learning curve, and the majority of other resistances are ramifications stemming from the learning curve".

\subsubsection{Question 3}

"What have been the main advantages and disadvantages for implementing BIM on lower value projects and overall would companies or individuals recommend BIM on lower value projects?"

The data highlighted that one of the biggest advantages of using BIM was the significant improvement of visualisations, which benefited the design team, client and contractors. This means that even by implementing BIM 'Level One' (refer to Section 1.1) on a project, that project would receive significant advantages.

Even though most of the respondents that replied were from the design side of the workflow, a number of advantages were directed towards contractors. One aspect is that the contractor receives a fully quantified and accurate set of drawings and schedules to a much higher level of quality and accuracy than previously produced without BIM. This allows the contractor to tender the job at a higher level of accuracy and therefore further reduce the risk to the project, which will be beneficial to all parties.

One respondent highlighted that they would use BIM on any project, since by investing in it early on in the process it will pay dividends by reducing risks during the construction stage.

With regards to the disadvantages of using BIM, the majority of the factors highlighted in this study were external to the methodology itself. There is a large learning curve, both technically and in the way project designs are delivered. It was highlighted multiple times that the current design fee and time structure has not been changed to reflect the required upfront investment within the BIM design process. However, some respondents felt that this was common on larger projects and not limited to smaller valued projects.

The data analysis within this report noted that the majority of the disadvantages highlighted would be reduced significantly or even eradicated once BIM integration had been fully achieved. 


\subsection{Discussion of results}

\subsubsection{Size of company}

The study found that smaller companies (1-10 employees) had a much higher percentage of respondents who have not used BIM when compared to larger companies (30+ employees). However, when the data is grouped together differently in terms of people who have implemented BIM on most or all projects and those who have not, the implementation rates are almost the same: $38 \%$ compared to $41 \%$ respectively.

This finding contradicts the literature review where it was found that the implementation rate of BIM in smaller consultancies is lower than in larger consultancies. This could be because of the sample of respondents and/or literature's definition of BIM implementation. The study found that there are a lot more people in larger companies who are only seldom using BIM. However, it does support the notion that it is easier and quicker for smaller companies to implement BIM within their workflow, compared with larger ones.

\subsubsection{Perceived client demand}

From the individual questionnaire results, the study found that the perceived client demand is low on both sides of the implementation spectrum. However, within the project insights questionnaires, one key stakeholder who requested the level of BIM was the client. These two results appear to contradict each other and dilutes the perceived view that client demand for BIM is low. The project data set was weak, so it is not possible to comment conclusively, but nonetheless, there is a level of perceived client demand in other publications. The biggest client demand highlighted within the literature review is the Government itself, requiring BIM to be implemented by 2016 in their projects.

It is worth noting that just because current client demand may be low for a product, it does not mean that something is not suitable. There have been many examples throughout time that this is the case. One such example is Johannes Gutenberg, who invented the printing press in the 15 th century at a time when the majority of the population was illiterate [14]. For the first time, books became relatively affordable. People now had access to books; it motivated them to learn to read, which in turn significantly increased client demand [14]. This may be one of the reasons why, in the previous paragraph contradictions were found between clients; some clients are illiterate in terms of BIM, do not understand it, and therefore dismiss it, and there are clients that are literate in terms of BIM, have seen the benefits and therefore demand its use. This could mean that when more clients become literate in BIM, the client's demand will increase, which in turn will increase the perception of the suitability of BIM, both on lower and higher value projects.

\section{Conclusions}

The conclusion section of this study had been split into three sections: Limitations and Further Study, Conclusions and Summary of Key Findings. 


\subsection{Limitations and further study}

Further study into the workflow of smaller projects could be carried out. The study could enquire into how previous projects have scaled down the BIM methodology to suit the needs of their project, and what their major lessons learned through that process were. At the same time, this will highlight a better understanding on the practical aspects of the methodology. In particular, the added value and client demand should be considered, since, ultimately, the client's requirements will dictate the level of detail that will be contained within the BIM model.

\subsection{Conclusions}

Based on the data collected throughout the study, it can be concluded that companies and individuals have not implemented BIM; not because of the methodology itself, but because of the perceived learning curve and perceived capital cost. Once over the learning curve and having outlaid the capital expenditure, individuals and companies experience advantages that surpass their investment.

The results indicate that it is easier and quicker to implement BIM within a smaller practice. Larger companies appear to have a lot of personnel that are only using BIM occasionally, which indicates it could be harder to fully implement BIM within their workflow.

It was interesting to see the difference in opinion between individuals who have and have not implemented BIM. In general, people who are not using BIM are concerned about the lack of external demand and an increase in perceived capital cost. Whereas, generally, people who have fully integrated BIM into their workflow would recommend BIM on the majority of their projects, purely because of the benefits they receive directly. Any other subsequent external benefits add further value to the project.

Confidence of BIM's suitability dramatically increases once the project value increases above $£ 500,000$. However, the study has not found evidence to suggest that the BIM methodology is unsuitable on projects of any value. Most resistance has been in the direction of its implementation; again relating to the learning curve of the individual and industry. In other words, once fully integrated, the resistances and disadvantages will be limited.

The methodology will need to be adapted to suit each project situation, no matter what size or sector; similar to some other aspects of the construction industry. Thus, this investigation can conclude that BIM Level Two is suitable for all project values on the proviso that the methodology is changed to suit the clients and project teams' needs.

\subsection{Summary of key findings}

The study's key findings can be summarised as follows:

- BIM is suitable on projects of all values, provided it is adapted to suit the project. It is noted that project value is not the sole factor when considering 
how BIM is going to be used; there are many other factors that will influence the requirements of the BIM model.

- The advantages and disadvantages of BIM are common to both large and small value projects, with the learning curve being the key resistance to implementation.

- There is no justification for the slower rate of BIM implementation on smaller projects. On the contrary, results and publications indicate it is easier to implement BIM fully in smaller consultancies.

- BIM's perceived suitability is proportional to the individual's experience of BIM.

\section{References}

[1] National BIM Report 2014, NBS, Online. http://www.thenbs.com/ pdfs/NBS-National-BIM-Report-2014.pdf

[2] A report for the Government Construction Client Group Building Information Modelling (BIM) Working Party Strategy Paper, BIM Task Group, Online. http://www.bimtaskgroup.org/wp-content/uploads/2012/03/ BIS-BIM-strategy-Report.pdf

[3] Construction-Operations Building Information Exchange, East, B., Online. http://www.wbdg.org/resources/cobie.php

[4] Industry Strategy - Government and Industry in Partnership Building Information Modelling, HM Government, Online. https://www.gov.uk/ government/uploads/system/uploads/attachment_data/file/34710/12-1327building-information-modelling.pdf

[5] Building Information Modelling, Out-Law, Online. http://www.outlaw.com/en/topics/projects--construction/projects-and-procurement/ building-information-modelling/

[6] Building Information Modelling (BIM): Now and Beyond, Azhar, S., Khalfan, M. \& Maqsood T., Online. http://epress.lib.uts.edu.au/journals/ index.php/AJCEB/article/view/3032

[7] Klaschka, R. BIM in Small Practices: Illustrated Case Studies. 134th Ed. London \& New York: Taylor \& Francis, 2014.

[8] Dawes, L., BIM: Reducing Complexity without Losing Clarity, Online. http://cic.org.uk/blog/article.php?s=2014-01-23-bim-reducing-complexitywithout-losing-clarity

[9] Sebastian, R., Haak, W., Vos, E., Tuckman, B., BIM Application for Integrated Design and Engineering in Small-Scale Housing Development: A Pilot Project in The Netherlands', International Symposium CIB-W096 "Future Trends in Architectural, Management", Online. http://www.inproproject.eu/media/R_SEBASTIAN_BIM_Application_for_Integrated_D_a nd_E_in_Small-Scale_Housing_Development_Pilot_Project.pdf

[10] Miller, $\bar{D}$., BIM from the point of view of a small practice, Online. https://www.thenbs.com/topics/BIM/articles/bimSmallPractice.asp 
[11] Bryde, D., Broquetas, M. \& Marc Volm, J. 'The Project Benefits Of Building Information Modelling (BIM)', International Journal of Project Management, vol. 31, pp. 971-980, 2013.

[12] Bridging Gap between BIM \& Residential Owners, Architectural, Online. http://www.architecturalevangelist.com/building-informationmodeling/bridging-gap-between-bim-residential-owners.html

[13] 'What is grounded theory?' Grounded Theory Online, Scott, H, Online. http://www.groundedtheoryonline.com/what-is-grounded-theory

[14] "The Impact of the Printing Press", SKWIRK, Online. http://www.skwirk.com/p-c_s-56_u-422_t-1108_c-4280/the-impact-ofthe-printing-press/qld/the-impact-of-the-printing-press/renaissance-andreformation/the-reformation 